\title{
Predictors of sedentary status in overweight and obese patients with multiple chronic conditions: a cohort study
}

\author{
Mark $\mathrm{H}$ Joven \\ Ivana T Croghan \\ Stephanie M Quigg \\ Jon O Ebbert \\ Paul Y Takahashi
}

Division of Primary Care Internal Medicine, Mayo Clinic, Rochester, Minnesota, MN, USA
Correspondence: Paul Y Takahashi Division of Primary Care Internal Medicine, Mayo Clinic, 200 First St SW, Rochester, MN 55905, USA Email takahashi.paul@mayo.edu
This article was published in the following Dove Press journal:

Pragmatic and Observational Research

3 October 2017

Number of times this article has been viewed

Purpose: Walking may improve health in obese patients with multimorbidity. We aimed to identify predictors associated with achieving $<5000$ steps per day after 4 months.

Patients and methods: We conducted a cohort study of 125 adult patients with a body mass index $>25 \mathrm{~kg} / \mathrm{m}^{2}$ and $\geq 7$ comorbidities. We evaluated potential predictors for $<5000$ steps per day using logistic regression and adjusting for age $>65$ years and sex.

Results: The mean (range) age was $63.6(20.3-89.8)$ years. Daily step counts $<5000$ at baseline showed the highest risk of $<5000$ daily steps at 4 months (odds ratio [OR] 31.82, 95\% confidence interval [CI]: 12.14-95.50). Other significant characteristics were physical quality of life (OR 6.21, 95\% CI: 2.32-18.54), gait speed $<1 \mathrm{~m} / \mathrm{s}$ (OR 2.57, 95\% CI: 1.18-5.71), age $\geq 65$ years (OR 2.21, 95\% CI: 1.05-4.77), waist circumference $\geq 102 \mathrm{~cm}$ (OR 2.48, 95\% CI: 1.05-6.06), and body mass index $\geq 30 \mathrm{~kg} / \mathrm{m}^{2}$ (OR $2.69,95 \%$ CI: $1.20-6.26$ ).

Conclusion: New models to increase walking may be required for higher-risk patients.

Keywords: multimorbidity, obesity, pedometer, walking

\section{Introduction}

The prevalence of obesity, defined as a body mass index (BMI) $\geq 30 \mathrm{~kg} / \mathrm{m}^{2}$, has a mean ( $95 \%$ confidence interval [CI]) of 34.9\% (32.0\%-37.9\%) among US adults aged $\geq 20$ years. The National Health and Nutrition Examination Survey (NHANES) from 2011 to 2012 reported that, on average, $68.5 \%$ (95\% CI, 65.2\%-71.6\%) of persons were either overweight (BMI $\geq 25$ but $<30 \mathrm{~kg} / \mathrm{m}^{2}$ ) or obese. ${ }^{1}$ Obesity is associated with metabolic syndrome, characterized by dyslipidemia (e.g., high level of triglycerides, low level of high-density lipoprotein cholesterol [HDL-C]), impaired fasting glucose, and hypertension. Metabolic syndrome increases the risks of cardiovascular disease and type 2 diabetes mellitus, ${ }^{2}$ and sedentary behaviors increase the risks of metabolic syndrome, ${ }^{3}$ type 2 diabetes mellitus, cardiovascular disease, and death. ${ }^{4}$ All-cause mortality risk increases progressively as BMI exceeds $25.0 \mathrm{~kg} / \mathrm{m}^{2} .^{5}$

Lower levels of physical activity have been associated in $9 \%$ of premature death. This is projected to increase in the coming years. ${ }^{6}$ It is estimated to be the cause of $6 \%$ of coronary artery disease and about $7 \%$ of type 2 diabetes mellitus worldwide. ${ }^{6}$ In contrast, higher levels of physical activity have been associated with lower rates of chronic disease, cardiovascular disease, and type 2 diabetes mellitus. ${ }^{6,7}$ Reductions in blood pressure (decrease in systolic blood pressure by $2-5 \mathrm{mmHg}$ and in diastolic blood pressure by $1-4 \mathrm{mmHg}$ ), as well as decreases in levels of low-density lipoprotein cholesterol and non-HDL-C, have been observed with aerobic physical activity. ${ }^{7}$ In a 
population-based sample of 60-year-old persons, increased physical activity was associated with improved cardiovascular health. ${ }^{8}$ Considerable interest exists about increasing the aerobic activity of patients with medical comorbidities. Increasing step counts can have positive effects on health. When patients used a pedometer, they had decreased BMI by a mean $(95 \% \mathrm{CI})$ of $0.38(0.05-0.72) \mathrm{kg} / \mathrm{m}^{2}$ and systolic blood pressure by a mean $(95 \% \mathrm{CI})$ of $3.8(1.7-5.9) \mathrm{mmHg} .{ }^{9}$ Among patients with musculoskeletal concerns, an increase of 1950 steps per day showed improvements in disability, strength, and pain scores. ${ }^{10}$ However, the positive effects of an increased step count on health outcomes have not been seen in all studies. The ASUKI Step study, a 6-month pedometerbased intervention performed at the Arizona State University in the Phoenix area of Arizona and the Karolinska Institutet in Stockholm, Sweden, showed no significant change in BMI, but a decrease of $3.0 \mathrm{~cm}$ in waist circumference was observed at the end of the trial. ${ }^{11}$

The available literature is limited about barriers to physical activity. A survey of 5167 persons in Canada aged 15-79 years found that educational attainment, family income, self-rated health, intentions, self-efficacy scores, perceived barriers, perceived health benefits, and facility availability were factors associated with physical activity behaviors. ${ }^{12}$ A cross-sectional study of overweight and obese persons in Iran with type 2 diabetes mellitus identified barriers to physical activity that included negative attitude toward physical activity, discouragement, physical problems, cost, and environmental factors. ${ }^{13}$ Barriers more specific to older obese and overweight persons with multiple chronic conditions, have not been identified.

We previously performed a randomized controlled trial of goal setting and pedometer use among obese patients with multiple chronic conditions. ${ }^{14}$ Step counts (the primary outcome) did not increase significantly with this intervention ( $p=0.08$ ). Patient factors likely had a role in preventing engagement in increased activity, but these factors have not been elucidated. Our primary aim was to identify risk factors for walking $<5000$ steps per day for overweight and obese patients with multiple chronic health conditions. Identifying these risk factors may guide future interventions to increase step count and activity.

\section{Research design Study design}

We conducted a secondary analysis of a published clinical trial ${ }^{14}$ using a cohort design. In this trial, patients were randomly assigned to either immediate pedometer use plus behavioral goal setting in the form of SMART (specific, meaningful, action-based, realistic, and timely) goals or delayed pedometer use plus delayed goal setting. Patients in the delayed group received the intervention with pedometer and SMART goals at 2 months. The SMART goals were used from previously published principles of formulating personalized and specific goals. ${ }^{15}$ This model is based on the transtheoretical model of change where the SMART goals help move the participant to action. The study was reviewed and approved by the Mayo Clinic Institutional Review Board.

\section{Setting}

The initial clinical study was completed at a clinical center in Rochester, Minnesota (Clinical Trial Number: NCT01833507). Study enrollment occurred from May 1, 2013, through September 10, 2014. Patients had a face-to-face visit with the study coordinator, and written informed consent was obtained. ${ }^{16}$

\section{Participants}

Study participants were 130 community-dwelling persons who were overweight or obese (BMI, 25.0-29.9 kg/m ${ }^{2}$ and $\geq 30 \mathrm{~kg} / \mathrm{m}^{2}$, respectively) and had $\geq 7$ comorbid chronic conditions based on outpatient and inpatient billing codes. All enrolled participants received primary care through Mayo Clinic to reduce referral bias. This disease burden of 7 or more conditions correlates with extended or complex tiering (tier 3 or 4) based on the Minnesota Tiering Model, a clinical risk stratification method. ${ }^{17}$ This was calculated by a trained medical staff not involved in the study. Participants who were excluded were either enrolled in hospice or wheelchairbound, had uncontrolled depression (Patient Health Questionnaire 9 [PHQ-9] scores $\geq 10$ ), ${ }^{18}$ or had documented dementia in accordance with the Short Test of Mental Status ${ }^{19,20}$ (scores $\leq 29 / 38$ ). Patients were excluded if they lived in a skilled nursing or correctional facility. Patients were also excluded if they refused medical record review. All patients who had available step data at the end of the original study were included in the present study.

\section{Outcome}

The primary outcome was attainment of $<5000$ steps per day on average, as recorded by a pedometer at 4 months. Achieving $<5000$ steps per day has been considered to be sedentary status by some investigators ${ }^{21}$ and thus, the determination of a cut-off of 5000 steps. All participants were seen at baseline and had baseline information collected. 


\section{Predictors}

The demographic, medical, and anthropomorphic data were collected. These included age, race, sex, elder risk assessment (ERA) score, ${ }^{22}$ BMI, baseline systolic blood pressure, and waist circumference. Age was dichotomized as $<65$ years and $\geq 65$ years on the basis of potential enrollment in Medicare. We dichotomized ERA score into $\geq 16$, which represented the highest risk of hospital admission. ${ }^{22}$ We used a BMI cutoff score of $\geq 30 \mathrm{~kg} / \mathrm{m}^{2}$ to represent persons with obesity. ${ }^{23}$ We used cutoffs of systolic blood pressure $>150 \mathrm{mmHg}^{24}$ and waist circumference of $>102 \mathrm{~cm}$, as well as a cutoff of $<50$ for both the physical component summary (PCS) and the mental component summary (MCS) of the 12-Item Short Form Survey (SF-12). ${ }^{25}$ For grip strength, our cutoff was $<25 \mathrm{~kg}$. For $4 \mathrm{~m}$ walk time, we dichotomized at $<4 \mathrm{~s}$ for a calculated gait speed of $1.0 \mathrm{~m}$ per s. ${ }^{26}$

The team obtained baseline average steps per day, grip strength, and gait speed to identify potential factors at baseline that may affect sedentary status after 2 or 4 months of pedometer use. Grip strength was measured in pound per 1 inch squared using a hydraulic hand dynamometer (Baseline, Fabrication Enterprise, White Plains, NY, USA). Handheld dynamometers are considered a practical modality to assess muscle strength. ${ }^{27}$ The immediate pedometer group used a pedometer for 4 months (Omron HJ-112; Omron Healthcare, Inc., Bannockburn, IL, USA); the delayed pedometer group used the pedometer for 2 months. ${ }^{28,29}$ Length of actual pedometer use was also assessed. Research Electronic Data Capture (Mayo Clinic, Rochester, MN, USA) was used to computerize the collected data that were initially logged in paper. ${ }^{30}$

Patients completed the PHQ- $9^{18}$ and the SF- $12 .{ }^{25}$ The PHQ-9 assesses mood; scores $\geq 9$ indicate a possible depressive disorder. ${ }^{18}$ Physical and mental quality of life (QoL) was measured by SF-12 Health Survey at baseline, a valid measure of physical and mental functioning, as well as overall health-related QoL. The SF-12 is a questionnaire that contains 2 components of health summary - PCS and MCS - with higher scores indicating better perception of health..$^{25,31,32}$ The SF-12 uses a normalized mean of 50 for each subscore and 10 points for $\mathrm{SD}^{25}$

\section{Statistical methods}

The present analysis was conducted on patients who had available step data. For power calculations, we used all available information. We compared the demographic characteristics, biometric information, pedometer use, and self-reported data between the 2 groups at baseline. For continuous variables, we reported mean and SD for the over- all cohort and for persons who had $\geq 5000$ steps and those with $<5000$ steps. We also categorized each predictor into a binary 2 -group method. We split age into $>65$ years and $\leq 65$ years. We presented descriptive data for both continuous and dichotomized information. We used available information for determination of significance of predictors. We compared persons with $<5000$ steps per day to those with $\geq 5000$ steps using logistic regression unadjusted and adjusted for age $>65$ years and sex. We calculated odds ratios (ORs) with respective $95 \%$ CIs. $p$-values were obtained for each measurement to determine statistical significance, with $p<0.05$ considered significant. All analyses were conducted using JMP statistical software (SAS Institute Inc., Cary, NC, USA).

\section{Results \\ Participants}

Of 244 potential participants, 130 patients consented in the initial study, with 125 patients with step data for analysis (Table 1). Patients who had $<5000$ steps per day had a mean (SD) age of 66.4 (12.3) years versus 59.6 (16.8) years for those with $\geq 5000$ steps. Of the patient population, $98 \%$ were white and $73 \%$ were women, and 71 of the 125 patients $(57 \%)$ had $<5000$ steps daily at the end of 4 months.

\section{Predictors of $<5000$ steps per day}

After adjusting for age $>65$ years and sex, we found 6 predictors of $<5000$ steps per day (Table 2). We observed that patients aged $>65$ years had higher odds of $<5000$ steps (adjusted OR 2.21, 95\% CI: 1.05-4.77) compared with patients aged $\leq 65$ years. BMI $\geq 30 \mathrm{~kg} / \mathrm{m}^{2}$ also had higher odds of $<5000$ steps per day (adjusted OR 2.69, 95\% CI: 1.20-6.26). Waist circumference $>102 \mathrm{~cm}$ showed higher odds of $<5000$ steps (adjusted OR 2.48, 95\% CI: 1.05-6.06) compared with waist circumference $\leq 102 \mathrm{~cm}$. No association was found with white race, female sex, or systolic blood pressure $>140 \mathrm{mmHg}$ and $<5000$ steps per day.

For functional and emotional predictors, the strongest predictor of $<5000$ steps involved having $<5000$ steps at 2 months of measurement (adjusted OR 31.83, 95\% CI: 12.14-95.50) (Table 2). Thus, patients who had $<5000$ steps at the midway measurement point were likely to continue to have $<5000$ steps. We did not observe an association between the length of pedometer wearing time and the status of $<5000$ steps at 4 months, an observation consistent with the original trial findings. ${ }^{14} \mathrm{~A}$ self-rated physical QoL score $<50$ had higher odds of $<5000$ steps at 4 months (adjusted OR 6.21, 95\% CI: 2.32-18.54). Patients who required $>4 \mathrm{~s}$ to walk $4 \mathrm{~m}$ (gait speed, $<1 \mathrm{~m}$ per s) also had higher odds 
Table I Demographic and biometric characteristics at baseline

\begin{tabular}{|c|c|c|c|}
\hline Characteristic $^{a}$ & Overall $(N=\mid 25)^{b}$ & $\begin{array}{l}\text { Patients who had } \geq 5000 \\
\text { steps per day at } 4 \text { months } \\
(n=54)^{b}\end{array}$ & $\begin{array}{l}\text { Patients who had }<5000 \\
\text { steps per day at } 4 \text { months } \\
(n=7 I)^{b}\end{array}$ \\
\hline \multicolumn{4}{|l|}{ Demographic } \\
\hline Age, mean (SD), year & $63.5(15)$ & $59.6(16.8)$ & $66.4(12.8)$ \\
\hline Age $>65$ years & $63(50)$ & $22(4 I)$ & $4 \mid(58)$ \\
\hline White race & $122(98)$ & $53(98)$ & $69(97)$ \\
\hline Female sex & 91 (73) & $38(70)$ & $53(75)$ \\
\hline ERA score, mean (SD) & $6.3(5.4)$ & $4.9(4.9)$ & $7.3(5.6)$ \\
\hline ERA score $\geq 16$ & $8(6)$ & I (2) & $7(10)$ \\
\hline \multicolumn{4}{|l|}{ Biometric } \\
\hline BMI, mean (SD), kg/m² & $33.8(5.9)$ & $32.4(4.6)$ & $34.8(6.6)$ \\
\hline $\mathrm{BMI}>30 \mathrm{~kg} / \mathrm{m}^{2}$ & $86(69)$ & $32(59)$ & $54(76)$ \\
\hline Systolic blood pressure, mean (SD), $\mathrm{mmHg}$ & $130(14.1)$ & $127.6(13.1)$ & $131.9(14.7)$ \\
\hline Systolic blood pressure $>140 \mathrm{mmHg}$ & $3 I / / 24(25)$ & II (20) & $20 / 70(29)$ \\
\hline Waist circumference, mean (SD), cm & $113(15)$ & $109(13)$ & $117(16)$ \\
\hline Waist circumference $>102 \mathrm{~cm}$ & $93(74)$ & $36(67)$ & $57(80)$ \\
\hline \multicolumn{4}{|l|}{ Functional and emotional status } \\
\hline Pedometer intervention at 4 months & $63(50)$ & $29(54)$ & $34(48)$ \\
\hline PHQ-9, mean (SD) & $2.9(2.6)$ & $2.9(2.8)$ & $2.9(2.4)$ \\
\hline Physical QoL score, mean (SD), PCS & $40.8(9.4)$ & $44.2(8.8)$ & $38.3(9.1)$ \\
\hline Physical QoL score $<50$ PCS & $97 / 123(79)$ & $34 / 53(64)$ & $63 / 70(90)$ \\
\hline Mental QoL score, mean (SD) MCS & $54.1(8.1)$ & $53.8(8.3)$ & $54.3(8.0)$ \\
\hline Mental QoL score $<50$ MCS & $31 / 123(25)$ & $13 / 53(25)$ & $18 / 70(26)$ \\
\hline Steps at 2 months, mean (SD) & $4895(2806)$ & $6867(2228)$ & $3395(2169)$ \\
\hline Steps $<5000$ at 2 months & $74(59)$ & II (20) & $63(89)$ \\
\hline Grip strength, mean (SD), kg & $24.7(9.0)$ & $26.2(9.0)$ & $23.5(9.0)$ \\
\hline Grip strength $<25 \mathrm{~kg}$ & $70(56)$ & $28(52)$ & $42(59)$ \\
\hline Gait speed over $4 \mathrm{~m}$, mean (SD), s & $4.5(1.3)$ & $4.0(0.9)$ & $4.9(1.4)$ \\
\hline Gait time $>4 \mathrm{~s}$ & $73(58)$ & $24(44)$ & $49(69)$ \\
\hline
\end{tabular}

Notes: aValues are presented as number and percentage of patients unless specified otherwise. ${ }^{b}$ Where the number of patients is less than the number cited in the column heading, the patient number is listed as a denominator.

Abbreviations: BMI, body mass index; ERA, elder risk assessment; Ib/in², pound per inch squared; MCS, mental component summary; PCS, physical component summary; PHQ-9, Patient Health Questionnaire 9; QoL, quality of life.

Table 2 Clinical characteristics and odds of achieving $<5000$ steps per day at 4 months

\begin{tabular}{|c|c|c|c|c|}
\hline Characteristic $^{\mathrm{a}}$ & OR $(95 \% \mathrm{Cl})$ & $\begin{array}{l}\text { Unadjusted } \\
\text { p-value }^{\mathrm{b}}\end{array}$ & $\begin{array}{l}\text { Age- }(>65 \text { years }) \text { and sex- } \\
\text { adjusted OR }(95 \% \mathrm{Cl})\end{array}$ & $\begin{array}{l}\text { Adjusted } \\
\text { p-value }^{b}\end{array}$ \\
\hline Age $>65$ years & $1.99(0.97-4.12)$ & 0.06 & $2.21(1.05-4.77)$ & $0.04^{c}$ \\
\hline White race & $0.65(0.06-7.37)$ & 0.72 & $0.49(0.02-5.35)$ & 0.55 \\
\hline Female sex & $1.24(0.56-2.74)$ & 0.59 & $1.57(0.68-3.67)$ & 0.29 \\
\hline ERA score $\geq 16$ & $1.98(0.97-4.12)$ & 0.06 & $5.17(0.86-99.1)$ & 0.07 \\
\hline $\mathrm{BMI}>30 \mathrm{~kg} / \mathrm{m}^{2}$ & $2.18(1.02-4.77)$ & $0.045^{c}$ & $2.69(1.20-6.26)$ & $0.02^{c}$ \\
\hline Systolic blood pressure $>140 \mathrm{mmHg}$ & $1.56(0.68-3.72)$ & 0.30 & $1.40(0.58-3.55)$ & 0.46 \\
\hline Waist circumference $>102 \mathrm{~cm}$ & $2.19(0.97-5.10)$ & 0.06 & $2.48(1.05-6.06)$ & $0.04^{c}$ \\
\hline Pedometer intervention at 4 months & $0.79(0.39-1.61)$ & 0.52 & $0.80(0.37-1.62)$ & 0.50 \\
\hline Physical QoL score $<50$ PCS & $5.02(2.00-13.99)$ & $<0.001^{\mathrm{c}}$ & $6.21(2.32-18.54)$ & $<0.00 I^{\mathrm{c}}$ \\
\hline Mental QoL score <50 MCS & $\mathrm{I} .07(0.47-2.46)$ & 0.88 & $1.19(0.5 \mathrm{I}-2.84)$ & 0.69 \\
\hline Steps $<5000$ at 2 months & $30.78(12.05-88.39)$ & $<0.00 I^{\mathrm{c}}$ & $31.83(12.14-95.50)$ & $<0.00 I^{\mathrm{c}}$ \\
\hline Grip strength $<25 \mathrm{~kg}$ & $1.34(0.66-2.76)$ & $0.4 I$ & $0.93(0.38-2.29)$ & 0.88 \\
\hline Time $>4 \mathrm{~s}$ to walk $4 \mathrm{~m}$ & $2.78(1.34-5.88)$ & $0.006^{c}$ & $2.57(I . \mid 8-5.7 I)$ & $0.02^{c}$ \\
\hline
\end{tabular}

Notes: ${ }^{2}$ Characteristics are at baseline with steps at 2 months of intervention. ${ }^{b}$ Statistical method was logistic regression and multivariable logistic regression. ${ }^{\text {Significant }}$ value after adjustment for age and sex.

Abbreviations: BMI, body mass index; $\mathrm{Cl}$, confidence interval; ERA, elder risk assessment; MCS, mental component summary; OR, odds ratio; PCS, physical component summary; QoL, quality of life. 
of $<5000$ steps (adjusted OR 2.57, 95\% CI: 1.18-5.71) than those who required $\leq 4 \mathrm{~s}$. Grip strength and self-rated mental QoL score were not associated with $<5000$ steps.

\section{Discussion}

In our cohort of overweight and obese patients with multiple chronic conditions, we observed that patients who were walking $<5000$ steps at 2 months after study initiation had a more than 30-fold increased likelihood of continuing to walk $<5000$ steps at the end of 4 months. We found that patients with slower walking speed and lower self-rated physical QoL score were also more likely to have $<5000$ steps, with adjusted ORs more than 2.5- and 6-fold greater, respectively. In addition, patients aged $\geq 65$ years with a BMI $\geq 30 \mathrm{~kg} / \mathrm{m}^{2}$ and waist circumference $\geq 102 \mathrm{~cm}$ had more than a 2 -fold increased risk of taking $<5000$ steps daily. These novel findings indicate that patients who are not walking, feeling physically poor, older, heavier, and walking slowly are more likely to not walk 5000 steps per day after 4 months. We did not observe a difference among patients who had 4 months of pedometer use compared with 2 months of pedometer use. Thus, patients most in need of increasing their step counts are those who are not achieving 5000 steps per day currently.

Using step count as an outcome seems reasonable as patients and health care groups attempt to quantify physical activity. Some investigators have suggested walking $~ 5000$ steps a day as a sedentary lifestyle index..$^{33}$ Among persons with age in the 40 s, walking $<5000$ steps per day is associated with obesity. ${ }^{34}$ The Tasped Prospective Cohort Study had a total of 2576 mostly overweight or normal weight patients ( $44.1 \%$ and $32.1 \%$, respectively) from 3 cohort studies (mean age, 58.8 years) who were observed for over 10 years in $90 \%$ of participants. ${ }^{35}$ Higher step counts linearly correlated with lower all-cause mortality rates (adjusted hazard ratio 0.94, 95\% CI: $0.90-0.98$ per 1000 steps; $p=0.004)$. Increasing baseline steps per day from $<1000$ to a 10,000-step guideline produced a mean $(95 \% \mathrm{CI})$ decline in mortality risk of $46 \%$ $(18 \%-65 \%)$.

Our observation about poor physical QoL score, slower gait speed, and lower step count is consistent with studies in different patient populations. In an Australian sample of 1232 inactive patients and among the patient group aged 60-78 years, injury and poor health were the most frequently cited barriers to physical activity. ${ }^{36}$ This finding differed from the groups aged 18-39 years, who stated that time was the biggest barrier to physical activity. A descriptive report of 75 American Indians (mean [SD] age, 58.5 [5.7] years), 81.3\% of whom had at least 1 self-reported chronic disease, showed that poor physical health, measured by SF-12 PCS, strongly correlated with various physical outcomes. Thus, perceived physical health and observed activity such as walking steps and gait speed may be risk factors for walking $<5000$ steps for obese patients with multiple chronic conditions. In our study, the mental QoL scores did not correlate with patients who achieved $<5000$ steps per day (adjusted $p$-value, 0.69 ). This result is consistent with some reported studies (Mansi et $\mathrm{al}^{37}$ and Humphreys et al $\left.{ }^{38}\right)$. In other studies, depressed mood was associated with lower physical activity level..$^{39,40}$ This lack of effect of mental QoL was not completely expected or explained.

In the present study, we did not observe that either short or extended pedometer use affected activity status. We hypothesize that directly addressing sedentary behaviors needs to be a component of any activity intervention. A meta-analysis of 33 studies by Prince and colleagues ${ }^{41}$ showed that interventions focusing on sedentary behaviors resulted in clinically meaningful decreases in sedentary time. Focus on physical activity and sedentary behaviors or physical activity components alone showed only modest reductions in sedentary time. Pedometer use with SMART goals did not affect step status in our clinical trial. ${ }^{14}$ Age $>65$ years, BMI $>35 \mathrm{~kg} / \mathrm{m}^{2}$, and waist circumference $>102 \mathrm{~cm}$ were also associated with $<5000$ steps at 4 months. The NHANES from 2005 to 2006 found an inverse relationship between step count and BMI and waist circumference in a cross-section of US patients. ${ }^{42}$ Thus, findings from an obese participant population with multiple chronic conditions mirror findings from the general US population.

These results have practical clinical applications. Providers routinely counsel overweight and obese patients on lifestyle modifications to improve and increase exercise, which is consistent with US Preventive Services Task Force guidelines. ${ }^{43}$ Providers should evaluate patient clinical characteristics to tailor the advice and therapeutic options. Obese or self-rated physically ill patients may have more problems implementing lifestyle interventions. Chronic disease and advanced age can negatively affect physical function. ${ }^{32}$ Further clinically practical research is needed to improve physical activity in this population.

The present study has practical limitations. Its sample size was small, and our findings have not been replicated in a different cohort. Data were collected prospectively, and data collection was complete. However, a risk of measurement error exists in the outcomes and predictors. In particular, the continuous application of the pedometer was not verified, 
and we cannot be certain it was used or worn correctly. An element of volunteer bias is possible because this cohort was taken from patients who volunteered for a prospective clinical trial. The study population was mostly white, which is reflective of the local population in the Upper Midwest of the USA. ${ }^{44}$ Despite these limitations, the study provides some initial utility in predicting who is at risk of $<5000$ steps after initiation of pedometer use and SMART goal setting.

\section{Conclusion}

Patients with step counts $<5000$ at 2 months, a physical QoL score $<50$, and a time to walk $4 \mathrm{~m}>4 \mathrm{~s}$ had increased odds of walking $<5000$ steps daily at 4 months. Age $>65$ years, BMI $>30 \mathrm{~kg} / \mathrm{m}^{2}$, and waist circumference $>102 \mathrm{~cm}$ also resulted in higher odds of $<5000$ steps. Patients who need help the most with their health (e.g., older, <5000 steps daily, obese, poor physical QoL) are those who are most likely to continue at $<5000$ steps per day. The use of pedometers and goal setting strategies might be one of prevention or activity maintenance for those patients who are already active. Different strategies may be required for patients with lower step counts or higher BMI.

\section{Acknowledgments}

We acknowledge the Mayo Clinic Division of Primary Care Internal Medicine and the Department of Medicine for their support in this research. We acknowledge the Center for Clinical and Translational Science grant support (UL1 TR000135) for the use of REDCap.

\section{Disclosure}

The authors report no conflicts of interest in this work.

\section{References}

1. Ogden CL, Carroll MD, Kit BK, Flegal KM. Prevalence of childhood and adult obesity in the United States, 2011-2012. J Am Med Assoc. 2014;311(8):806-814.

2. Alberti KG, Eckel RH, Grundy SM, et al; International Diabetes Federation Task Force on Epidemiology and Prevention; National Heart, Lung, and Blood Institute; American Heart Association; World Heart Federation; International Atherosclerosis Society; International Association for the Study of Obesity. Harmonizing the metabolic syndrome: a joint interim statement of the International Diabetes Federation Task Force on Epidemiology and Prevention; National Heart, Lung, and Blood Institute; American Heart Association; World Heart Federation; International Atherosclerosis Society; and International Association for the Study of Obesity. Circulation. 2009;120(16):1640-1645.

3. Edwardson CL, Gorely T, Davies MJ, et al. Association of sedentary behaviour with metabolic syndrome: a meta-analysis. PLoS One. 2012;7(4):e34916.

4. Wilmot EG, Edwardson CL, Achana FA, et al. Sedentary time in adults and the association with diabetes, cardiovascular disease and death: systematic review and meta-analysis. Diabetologia. 2012;55(11):28952905. Erratum in: Diabetologia. 2013;56(4):942-943.
5. Global BMI Mortality Collaboration. Body-mass index and all-cause mortality: individual-participant-data meta-analysis of 239 prospective studies in four continents. Lancet. 2016;388(10046):776-786.

6. Lee IM, Shiroma EJ, Lobelo F, Puska P, Blair SN, Katzmarzyk PT; Lancet Physical Activity Series Working Group. Effect of physical inactivity on major non-communicable diseases worldwide: an analysis of burden of disease and life expectancy. Lancet. 2012;380(9838):219-229.

7. Eckel RH, Jakicic JM, Ard JD, et al; American College of Cardiology/ American Heart Association Task Force on Practice Guidelines. 2013 AHA/ACC guideline on lifestyle management to reduce cardiovascular risk: a report of the American College of Cardiology/American Heart Association Task Force on Practice Guidelines. JAm Coll Cardiol. 2014;63(25 Pt B):2960-2984. Erratum in: $J$ Am Coll Cardiol. 2014;63(25 Pt B): 3027-3028.

8. Ekblom-Bak E, Ekblom B, Vikstrom M, de Faire U, Hellenius ML. The importance of non-exercise physical activity for cardiovascular health and longevity. Br J Sports Med. 2014;48(3):233-238.

9. Bravata DM, Smith-Spangler C, Sundaram V, et al. Using pedometers to increase physical activity and improve health: a systematic review. J Am Med Assoc. 2007;298(19):2296-2304.

10. Mansi S, Milosavljevic S, Baxter GD, Tumilty S, Hendrick P. A systematic review of studies using pedometers as an intervention for musculoskeletal diseases. BMC Musculoskelet Disord. 2014;15(1):231.

11. Walker JR, Soroush A, Ainsworth BE, Belyea M, Swan PD, Yngve A. US cohort differences in body composition outcomes of a 6-month pedometer-based physical activity intervention: the ASUKI Step Study. Asian J Sports Med. 2014;5(4):e25748.

12. Pan SY, Cameron C, Desmeules M, Morrison H, Craig CL, Jiang X. Individual, social, environmental, and physical environmental correlates with physical activity among Canadians: a cross-sectional study. $B M C$ Public Health. 2009;9(1):21.

13. Halali F, Mahdavi R, Asghari Jafarabadi M, Mobasseri M, Namazi N. A cross-sectional study of barriers to physical activity among overweight and obese patients with type 2 diabetes in Iran. Health Soc Care Community. 2016;24(5):e92-e100.

14. Takahashi PY, Quigg SM, Croghan IT, Schroeder DR, Ebbert JO. Effect of pedometer use and goal setting on walking and functional status in overweight adults with multimorbidity: a crossover clinical trial. Clin Interv Aging. 2016;11:1099-1106.

15. Bovend'Eerdt TJ, Botell RE, Wade DT. Writing SMART rehabilitation goals and achieving goal attainment scaling: a practical guide. Clin Rehabil. 2009;23(4), 352-361. Erratum in: Clin Rehabil. 2010; 24(4):382.

16. Takahashi PY, Naessens JM, Peterson SM, et al. Short-term and longterm effectiveness of a post-hospital care transitions program in an older, medically complex population. Healthcare (Amsterdam). 2016;4(1): $30-35$.

17. Haas LR, Takahashi PY, Shah ND, et al. Risk-stratification methods for identifying patients for care coordination. Am J Manag Care. 2013;19(9):725-732.

18. Kroenke K, Spitzer RL, Williams JB. The PHQ-9: validity of a brief depression severity measure. J Gen Intern Med. 2001;16(9):606-613.

19. Kokmen E, Smith GE, Petersen RC, Tangalos E, Ivnik RC. The short test of mental status: correlations with standardized psychometric testing. Arch Neurol. 1991;48(7):725-728.

20. Kokmen E, Naessens JM, Offord KP. A short test of mental status: description and preliminary results. Mayo Clin Proc. 1987;62(4):281-288.

21. Tudor-Locke C, Hatano Y, Pangrazi RP, Kang M. Revisiting "how many steps are enough?" Med Sci Sports Exerc. 2008;40(7 Suppl):S537-S543.

22. Crane SJ, Tung EE, Hanson GJ, Cha S, Chaudhry R, Takahashi PY. Use of an electronic administrative database to identify older community dwelling adults at high-risk for hospitalization or emergency department visits: the elders risk assessment index. BMC Health Serv Res. 2010; 10(1):338.

23. World Health Organization. BMI classification. [Internet]. 2014. Available from: http://apps.who.int/bmi/index.jsp?introPage=intro_3.html. Accessed January 1, 2017. 
24. James PA, Oparil S, Carter BL, et al. 2014 evidence-based guideline for the management of high blood pressure in adults: report from the panel members appointed to the Eighth Joint National Committee (JNC 8). J Am Med Assoc. 2014;311(5):507-520. Erratum in: J Am Med Assoc. 2014;311(17):1809.

25. Ware J Jr, Kosinski M, Keller SD. A 12-item short-form health survey: construction of scales and preliminary tests of reliability and validity. Med Care. 1996;34(3):220-233.

26. Fielding RA, Vellas B, Evans WJ, et al; International Working Group on Sarcopenia. Sarcopenia: an undiagnosed condition in older adults: current consensus definition: prevalence, etiology, and consequences. J Am Med Dir Assoc. 2011;12(4):249-256.

27. Stark T, Walker B, Phillips JK, Fejer R, Beck R. Hand-held dynamometry correlation with the gold standard isokinetic dynamometry: a systematic review. PM R. 2011;3(5):472-479.

28. Schneider PL, Crouter SE, Lukajic O, Bassett DR Jr. Accuracy and reliability of 10 pedometers for measuring steps over a $400-\mathrm{m}$ walk. Med Sci Sports Exerc. 2003;35(10):1779-1784.

29. Holbrook EA, Barreira TV, Kang M. Validity and reliability of Omron pedometers for prescribed and self-paced walking. Med Sci Sports Exerc. 2009;41(3):670-674.

30. Harris PA, Taylor R, Thielke R, Payne J, Gonzalez N, Conde JG Research electronic data capture (REDCap): a metadata-driven methodology and workflow process for providing translational research informatics support. J Biomed Inform. 2009;42(2):377-3781.

31. Ware JE, Kosinski M, Keller SD; New England Medical Center Hospital Health Institute. SF-12: How to Score the SF-12 Physical and Mental Health Summary Scales. 2nd ed. Boston, MA: Health Institute, New England Medical Center; 1995.

32. Hopman WM, Harrison MB, Coo H, Friedberg E, Buchanan M, VanDenKerkhof EG. Associations between chronic disease, age and physical and mental health status. Chronic Dis Can. 2009;29(3):108-116.

33. Tudor-Locke C, Bassett DR Jr. How many steps/day are enough? Preliminary pedometer indices for public health. Sports Med. 2004;34(1):1-8.

34. Tudor-Locke C, Ainsworth BE, Whitt MC, Thompson RW, Addy CL, Jones DA. The relationship between pedometer-determined ambulatory activity and body composition variables. Int J Obes Relat Metab Disord. 2001;25(11):1571-1578.
35. Dwyer T, Pezic A, Sun C, et al. Objectively measured daily steps and subsequent long term all-cause mortality: the tasped Prospective Cohort Study. PLoS One. 2015;10(11):e0141274. Erratum in: PLoSOne. 2015;10(12):e0146202.

36. Booth ML, Bauman A, Owen N, Gore CJ. Physical activity preferences, preferred sources of assistance, and perceived barriers to increased activity among physically inactive Australians. Prev Med. 1997;26(1): 131-137.

37. Mansi S, Milosavljevic S, Tumilty S, Hendrick P, Higgs C, Baxter DG. Investigating the effect of a 3-month workplace-based pedometer-driven walking programme on health-related quality of life in meat processing workers: a feasibility study within a randomized controlled trial. $B M C$ Public Health. 2015;15(1):410.

38. Humphreys DK, Goodman A, Ogilvie D. Associations between active commuting and physical and mental wellbeing. Prev Med. 2013;57(2):135-139.

39. Alosco ML, Spitznagel MB, Miller L, et al. Depression is associated with reduced physical activity in persons with heart failure. Health Psychol. 2012;31(6):754-762.

40. Yoshiuchi K, Nakahara R, Kumano H, et al. Yearlong physical activity and depressive symptoms in older Japanese adults: cross-sectional data from the Nakanojo study. Am J Geriatr Psychiatry. 2006;14(7): 621-624.

41. Prince SA, Saunders TJ, Gresty K, Reid RD. A comparison of the effectiveness of physical activity and sedentary behaviour interventions in reducing sedentary time in adults: a systematic review and meta-analysis of controlled trials. Obes Rev. 2014;15(11):905-919.

42. Tudor-Locke C, Schuna JM Jr, Han HO, et al. Step-based physical activity metrics and cardiometabolic risk: NHANES 2005-2006. Med Sci Sports Exerc. 2017;49(2):283-291.

43. LeFevre ML; US Preventive Services Task Force. Behavioral counseling to promote a healthful diet and physical activity for cardiovascular disease prevention in adults with cardiovascular risk factors: US Preventive Services Task Force Recommendation Statement. Ann Intern Med. 2014;161(8):587-593.

44. St Sauver JL, Grossardt BR, Leibson CL, Yawn BP, Melton LJ 3rd, Rocca WA. Generalizability of epidemiological findings and public health decisions: an illustration from the Rochester Epidemiology Project. Mayo Clin Proc. 2012;87(2):151-160.
Pragmatic and Observational Research

\section{Publish your work in this journal}

Pragmatic and Observational Research is an international, peer-reviewed open access journal that publishes data from studies designed to reflect more closely medical interventions in real-world clinical practice compared with classical randomized controlled trials (RCTs). The manuscript management system is completely online and includes a very quick and fair peer-review
Dovepress

system. Visit http://www.dovepress.com/testimonials.php to read real quotes from published authors. 